\title{
Optimization of Microgrid for Renewable Power Integration
}

\author{
Ujwala S. Raut ${ }^{1}$, Y. D. Shahakar ${ }^{2}$ \\ ME Student, Electrical Engineering, P. R. Pote (Patil) College of Engineering and Management, Amravati, India ${ }^{1}$ \\ Assistant Professor, Electrical Engg, P. R. Pote (Patil) College of Engineering and Management, Amravati, India ${ }^{2}$
}

\begin{abstract}
Over a century, human beings have consumed this easily available finite resource very inefficiently. This increasing energy consumption based on fossil reserves has resulted in financial instability, climate change, major depletion of the reserves, and political turmoil in the world. Initially generation of electricity from large power plants was encouraged; because it was considered to be more efficient than a large numbers of small dispersed power plants. Because of this trend in development along with depletion of fossil fuel reserves and the associated widespread environmental pollution, it has become urgent to find energy alternatives that are cost effective, sustainable and environment friendly. Renewable energy sources such as wind, solar, hydro and biomass provide energy security and will play an important role in the future to supply increasing global energy demand. Research and development in renewable energy technologies confirm that renewable energy sources are undoubtedly sustainable and that green technologies can shift global dependence away from fossil fuels.
\end{abstract}

Keywords: Microgrid, Optimization, Solar, Wind.

\section{INTRODUCTION}

The energy system proposed in this project aims to address issues related to electricity and transportation sectors. One of the potential solutions is a micro-grid that can be vertically integrated with a high-rise building as frequently encountered in urban areas. The harvesting of renewable wind and solar energy occurs at the top of the building. The rooftop generation system connects to the ground level via a micro-grid where electric vehicle (EV) charging stations are supplied, and a battery supports maintaining the balance of supply and demand. The potential value of an urban integration within buildings as considered here comes from the sources where rooftop energy generation is used, the storage of the latter for offering EV fast charging at the ground level, the colocation and integration of generation, the contribution to emission-free EV transportation in urban areas and load in urban areas, and the grid-friendly integration of the microgrid with the rest of the power system main grid. The combination of wind and solar energy leads to reduced local storage requirements and it was verified.

The combination of diverse but complementary storage technologies in turn can form multilevel energy storage, where super-capacitor or flywheel provides cache control to compensate for fast power fluctuations and to smoothen the transients encountered by a battery with higher energy capacity. Micro-grids or hybrid energy systems have been shown to be an effective structure for local interconnection of distributed renewable generation, loads, and storage.

Research Objectives

1) To optimize the cost and efficiency of microgrid using renewable sources

2) Comparison of hybrid (Wind and solar) with other system
3) Mathematical modelling of an optimization of microgrid and implementation

4) Comparison of results (Modelling and Simulation)

\section{LITERATURE SURVEY}

[1]In this paper, author presented the state-of-the-art on stochastic modelling and optimization tools for microgrid planning, operation, and control. The tools can be used to locate the randomness in renewable power generation, the buffering effect of energy storage devices and the mobility of PEVs in V2G systems. Furthermore, the unique features of micro-grid are the dual (islanded and grid-connected) operation modes, the spatial correlation of renewable power generation and the integration of CHP with both heat and electricity outputs, are taken into account.

[2]In this the author said that, Proportion of electricity produced from renewable energy sources records tremendous growth now days. It happened in accordance with strategies, which aim on decrease the production of greenhouse gases and carbon emissions. But, on the other hand it has results in so many changes and related problems in electric power system especially with its optimal operation control. It can be solved by growth of electricity, which can provide better integration of renewable energy sources due to its internment power supply and it also helps to prepare conventional distribution grids to new smart grid concept.

[3]In this, author told about St. Martin's Island which is a little Island in the Bay of Bengal about $9 \mathrm{~km}$ far from the main land of Bangladesh. Nearly 5000 residents live there and their primary livelihood is fishing and as a tourist spot 
there are many lodges and rest houses. Since the Island is far away from the conventional national grid connection, is almost unachievable even in future as a result of its geographical location. Locally installed diesel generator is used to provide electricity to inhabitants is established by power development board of Bangladesh but now it is not in working condition. In this paper, an effort has been made to design a model of micro-grid by means of hybrid electricity generation system for a small society of the Island. This system incorporates an arrangement of solar $\mathrm{PV}$, wind turbine, storage battery, biogas and diesel generator. MATLAB is software for optimization of renewable based amalgamative distributed generation systems has been used to find out the predominant technical effective renewable based energy efficient system for 650 family units. To perceive the impact of solar insulation, PV investment cost and wind speed and diesel fuel price on the optimum result the sensitivity analysis is also completed. During peak load the conferential diesel generator is switched on after covering demand by renewable source.

[4] In this paper, for the special case of a dc micro-grid that is vertically integrated within a high-rise host building of an urban area the controls are implemented. Previously untapped wind and solar power are harvested on the roof and sides of a tower, thereby supporting delivery to electric vehicles on the ground. The micro-grid vertically integrates with the host building without creating a large footprint.

[5]In this, the new concept in power generation is microgrid. The Micro-grid concept assumes array of loads and micro sources operating as a single controllable system which supplies both power and heat to its local area. Some models exist which describe the components of a microgrid. In this paper, model of micro-grids with steady state and their transient responses to changing inputs are presented. Current models of a wind turbine, fuel cell, micro-turbines and solar cell have been discussed. Finally a complete model built of micro-grid including the power sources, power electronics and a load and mains model in MATLAB/Simulink is presented.

[6]In this Integration of wind and solar within dc microgrids into a so-call net zero-energy buildings is studied. The dc ring microgrid is proposed to include a wind energy conversion system (WECS), a photovoltaic array (PV) and battery energy storage system (BESS). First, an optimized operation strategy in day ahead is presented to utilize maximum clean energy and minimum consumption of electricity from the main grid. Optimal generated power operation of the WECS and PV is run follows on the maximal power point tracking method (MPPT). Second, a coordinated droop scheme is introduced to provide coordination control of BESS and the main AC grid. Several simulations are performed to realize the presented method.

[7] The integration of wind, solar power and flying capacitor with DC micro grids. An aggregated model of renewable wind and solar power generation proposed to support the increases renewable energy sources and equilibrium of the micro grid's real-time supply and demand, implemented high-rise host building of an urban area. The MPPT controller incorporating an RPM algorithm was developed in consistence with the previous design of the perturbation parameters. The proposed control algorithms based on a VSIC method. This is easy to implement in simple microcontrollers and is fast as compared to normal fixed-step IC and perturb and observe algorithms. The RPM was used to limit the output power of the PV generator if the generation exceeds the system rating due to reduced ambient temperature and high solar radiation. This mode can also be used when there is excessive energy to be stored in a stand-alone system. The proposed algorithm has been validated by simulation and laboratory experiment. It can be seen that the proposed algorithm can prevent oscillation and is able to quickly track the optimal operating point in severe transient conditions with changes of solar radiation and temperature.

[8]In this project the data obtained from the DC micro grid constructed at Xiamen University shows that DC micro grid with rooftop solar system is an efficient way to power varies DC loads inside the building. To ensure the stable bus voltage and continuous operation of the DC micro grid, a suitable energy storage energy unit and two way AC/DC inverters are needed. Therefore we believe to use the solar power only for the matched DC loads, and keep existing AC power in the building to power the rest loads (or an AC and DC hybrid micro grid) maybe a more viable solution.

[9] In this project, a review of hybrid renewable/alternative energy (RE/AE) power generation system focusing on energy sustainability. It highlights some important issues and challenges in the design and energy management of hybrid RE/AE systems. System configurations, generation unit sizing, storage needs, and energy management and control are addressed. Statistics on the current status and future trend of renewable power generation, as well as some critical challenges facing the widespread deployment of RE/AE power generation technologies and vision for future research in this area are also presented.

[10] In this project reports the performance of $4 \mathrm{~kW}$ grid connected residential wind photovoltaic system (WPS) with battery storage located in Lowell, MA. The system was originally designed to meet a typical New-England (TNE) load demand with a loss of power supply probability (LPSP) of one day in ten years as recommended by the Utility Company.

\section{III.PROPOSED WORK}

The proposed strategy of operation is mainly determined on using an appropriate energy management and control strategies to enhance the operation of a dc micro-grid, 
formed by using a photovoltaic (PV) solar energy and wind, batteries, and loads

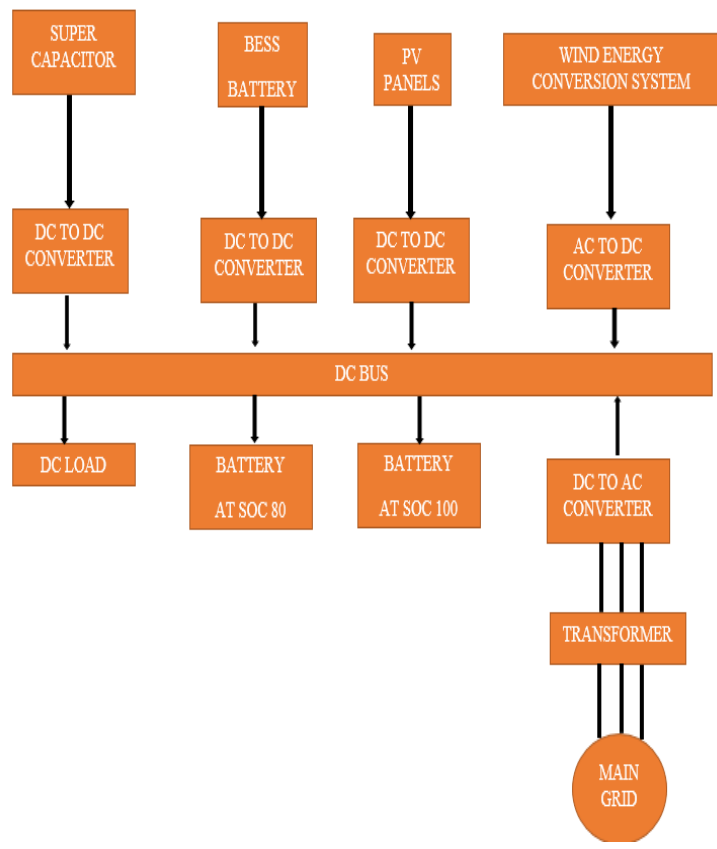

Fig.1 Proposed System Flow Chart

This control strategy is used to execute decentralized power management of a PV/battery hybrid unit in a droopcontrolled microgrid. To support the integration of wind and solar power within microgrids operational controls are designed. To support the quantification of the operational reserve for day-ahead and real-time scheduling an aggregated model of renewable wind and solar power generation forecast is proposed.

The proposed power/frequency characteristics, of the wind and solar combine unit and of the whole microgrid, adapt autonomously to the microgrid operating conditions so that the this unit may supply the maximum PV power, match the load, and/or charge the battery, while maintaining the power balance in the microgrid and respecting the battery SOC limits. By comparing with the existing droop controls, it is distinguished in that the droop curves are set as a function of the storage state-of-charge (SOC) and can become asymmetric. The adaptation of the slopes ensures that the power output supports the terminal voltage while at the same keeping the SOC within a target range of desired operational reserve.

\section{A. DC Microgrid}

A microgrid is a discrete energy system and it consists of distributed energy sources and loads capable of operating in parallel. Thus, the generation, storage and demand management of power will be easy. The primary purpose is to ensure local, reliable and flexible power for urban and rural communities, at the same time, providing solutions for commercial, industrial and federal government consumers. A micro grid also consists of distributed energy resources like solar PV systems and wind energy systems which have several electrical loads.

\section{B. Solar Energy}

The solar electric system consists of three major blocks, namely solar panels, PV cells, and batteries for storing energy. The electrical energy (DC power) generated using solar panels can be stored in batteries or can be used for supplying DC loads or we can use an inverter for feeding AC loads. The solar electric system output is electric power and is measured in terms of Watts or Kilowatts. These solar panels are designed with different output ratings like 100 watts, 5 watts, 10 watts, etc.

\section{Wind Power}

It is generated by using wind. It is the energy generation that uses actual form of wind through wind turbines, which rotate and generate electricity. For the generation of wind power we have many wind power equipment like wind turbines, water mills and windmills. The advantages of wind energy are wind turbine power generation, pumping water using wind pumps, mechanical power with windmills and so on. Here an electrical generator is coupled with a wind turbine hence it is named as a wind turbine generator. There are different types of wind turbine generators and these wind turbine generators can be directly connected to the power grid or loads or batteries based on different criteria.

\section{IV.CONCLUSION}

In this proposed implementation is a micro grid-connected hybrid PV-wind-battery- super capacitor based power evacuation scheme for various applications. The proposed hybrid system provides an elegant integration of PV and wind source to extract maximum energy from the two sources. It is realized by a novel multi-input transformer coupled bidirectional $\mathrm{dc}-\mathrm{dc}$ converter followed by a conventional full-bridge inverter.

A versatile control strategy which achieves a better utilization of PV, wind power, battery capacities without effecting life of battery, and power flow management in a grid-connected hybrid PV-wind-battery-based system feeding ac loads is implemented. Detailed simulation studies are carried out to ascertain the viability of the scheme. The experimental results obtained are in close agreement with simulations and are supportive in demonstrating the capability of the system to operate either in grid feeding or in stand-alone modes. The proposed configuration is capable of supplying uninterruptible power to ac loads, and ensures the evacuation of surplus PV and wind power into the grid.

\section{REFERENCES}

[1] Hao Liang and Weihua Zhuang "Stochastic Modeling and Optimization in a Microgrid: A Survey" Energies 2014, 7, 20272050; doi:10.3390/en7042027

[2] Martin VOJTEK (1st year) Supervisor: 2Michal KOLCUN "Optimization the operation of renewable energy sources in electric power system" IEEE TRANSACTIONS ON INDUSTRIAL ELECTRONICS, VOL. 61, NO. 8, AUGUST 2014.

[3] Md. Ruhul Amin1 Rajib Baran Roy2 and Md. Mahmudul Hasan3 "Modeling and Optimization of Decentralized Microgrid System 
Vol. 4, Issue 2, February 2017

for St. Martin's Island in Bangladesh" International Journal of Energy, Information and Communications Vol.5, Issue 5 (2014)

[4] "DC Microgrid for Wind and Solar Power Integration" IEEE JOURNAL OF EMERGING AND SELECTED TOPICS IN POWER ELECTRONICS, VOL. 2, NO. 1, MARCH 2014115

[5] Manzar Ahmed, Uzma Amin, Suhail Aftab, Zaki Ahmed "Integration of Renewable Energy Resources in Microgrid", Energy and Power Engineering, 2015, 7, 12-29.

[6] Duc Nguyen Huu, Hung Truong Nam," DC Microgrid for Buildings Integrated Renewable Energy Sources” December 2016.

[7] Chudaykiran, Mahesh," Integration of Renewable Energy Sources Wind and Solar Power Grid Connected Using MMPT \&Flywheel /Simulink.

[8] A. G. Madureira and J. A. Pecas Lopes, "Coordinated voltage support indistribution networks with distributed generation and microgrids," IET Renew. Power Generat., vol. 3, no. 4, pp. 439454, Dec. 2009

[9] MMPT \&Flywheel M. H. Nehrir, C. Wang, K. Strunz, H. Aki, R. Ramakumar, J. Bing, et al., "A review of hybrid renewable/alternative energy systems for electric power generation: Configurations, control, and applications," IEEE Trans. Sustain. Energy, vol. 2, no. 4, pp. 392-403, Oct. 2011.

[10] Simulinkdaykira F. Giraud and Z. M. Salameh, "Steady-state performance of a gridconnected rooftop hybrid wind-photovoltaic power system with battery storage," IEEE Trans. Energy Convers., vol. 16 , no. 1, pp. 1-7, Mar. 2001

[11] T. B. Johansson et al. "Renewable fuels and electricity for a growing world economy: Defining and achieving the potential," in Renewable Energy: Sources for Fuels and Electricity, Washington, D.C.: Island Press, 1993, pp. 1-7

[12] D. Holm, "Renewable energy future for the developing world," International Solar Energy Society, ISES Headquarters, Freiburg, Germany, White Paper, 2005. 